\title{
ZNAČAJ I KORIŠTENJE INFORMACIJA IZ FINANSIJSKIH IZVJEŠTAJA ZA POTREBE INTERESNIH GRUPA
}

\author{
Mirna Pajević́ ${ }^{1}$ Edin Glogić ${ }^{2}$, Sanela Agačević ${ }^{3}$ \\ ${ }^{1}$ Univerzitet u Sarajevu, Ekonomski fakultet u Sarajevu, Trg oslobođenja - Alija Izetbegović 1, Sarajevo, BiH; \\ ${ }^{2}$ Sveučilište/Univerzitet „VITEZ“, Fakultet poslovne ekonomije, Poslovni centar 96, Vitez, BiH; \\ ${ }^{3}$ Univerzitet u Zenici, Ekonomski fakultet Zenica, Travnička 1, Zenica, BiH
}

\begin{abstract}
Apstrakt:
Cilj ovog rada je da ukaže na značaj i ulogu korištenja finansijskih izvještaja koji pružaju informacije o finansijskom položaju i rezultatima poslovanja kompanije, što različitim interesnim grupama pomaže u donošenju odluka i formiranju stavova. Informacija je korisna ako ima utjecaja na odluke, a značajna ako njeno izostavljanje može promijeniti odluku i stavove korisnika finansijskih izvještaja. Predmet istraživanja ovog rada je analiza vrijednosne važnosti informacija iz finansijskih izvještaja. Uzorak čine kompanije, njih 72, iz realnog sektora sa područja Bosne i Hercegovine. Istraživanje pokazuje koje izvore informacija koriste različite interesne grupe prilikom donošenja odluka ili prilikom uvida u poslovanje, kao i značaj sastavljanja i objavljivanja finansijskih izvještaja općenito. Istraživanje potvrđuje značaj, ulogu i široku primjenu korištenja informacija iz finansijskih izvještaja od strane uprave, ulagača, kreditora i državnih institucija. Navedeni korisnici finansijskih izvještaja nastoje na temelju prezentovanih informacija donijeti kvalitetne poslovne odluke, a kvalitetne poslovne odluke zavise o kvaliteti pruženih informacija, prvenstveno zasnovanih na tačnosti, pouzdanosti i razumljivosti. Provedeno istraživanje dokazuje da interesne grupe prilikom donošenja odluka koriste finansijske izvještaje kao glavni izvor informacija i druge finansijske i nefinansijske informacije, stoga svi korisnici kao i kreatori finansijskih izvještaja trebaju raditi na unapređenju sastavljanja, izvještavanja i korištenja finansijskih izvještaja i drugih izvora.
\end{abstract}

\section{UVOD}

\subsection{Finansijski izvještaji}

Finansijski izvještaji imaju za cilj da prezentuju formalnu finansijsku aktivnost kompanije na kraju poslovnog perioda, odnosno poslovne godine. Sve relevantne informacije koje su vezane za poslovanje kompanije, a predstavljene prema unaprijed definisanim pravilima i procedurama na jednoobrazan i razumljiv način predstavljaju finansijske izvještaje. Pružanje finansijskih informacija opće namjene osobama izvan kompanije čini svrhu skupa računovodstvenih izvještaja koji se zovu finansijski izvještaji.

Osobe koje primaju i koriste informacije iz finansijskih izvještaja kompanije smatraju se korisnicima finansijskih izvještaja (Meigs \& Meigs, 1999).

Osnovni set finansijskih izvještaja u Bosni i Hercegovini čini pet povezanih izvještaja, koji sumiraju finansijska sredstva, obaveze, kapital, profitabilnost i novčane transakcije kompanije.

Osnovni set finansijskih izvještaja čine sljedeći izvještaji:

- Bilans stanja je finansijski izvještaj koji prezentuje finansijski položaj preduzeća na određeni datum, sredstva koja posjeduje, obaveze i kapital,
- Bilans uspjeha predstavlja izvještaj u kojem se prezentuje profitabilnost kompanije u određenom vremenskom periodu, ovaj izvještaj se još naziva i račun dobiti i gubitka,

- Izvještaj o promjenama u kapitalu je finansijski izvještaj koji za cilj ima prezentovanje promjena u odnosu na vlasnički kapital kompanije,

- Izvještaj o novčanim tokovima ima za cilj prezentaciju svih novčanih primitaka i novčanih izdataka, odnosno novčanih priliva i odliva u određenom vremenskom periodu i

- Bilješke uz finansijske izvještaje imaju zadatak da prezentuju dodatne informacije za koje računovođe smatraju da su korisne i značajne u interpretaciji finansijskih izvještaja.

Kompanije u Bosni i Hercegovini razvrstane u skladu sa važećim Zakonom o računovodstvu i reviziji kao srednja i velika pravna lica prilikom prezentacije finansijskih izvještaja koriste osnovni set finansijskih izvještaja, dok kompanije razvrstane kao mala pravna lica za prezentaciju koriste samo dio seta finansijskih izvještaja, odnosno bilans stanja i bilans uspjeha. 


\subsection{Stakeholders (interesne grupe)}

Stakeholders je termin koji predstavlja interesne grupe, odnosno organizacije, zajednice, individue, koje imaju direktan ili indirektan interes u odnosu na kompaniju ili koji svojim aktivnostima pozitivno ili negativno utječu na kompaniju i kompanija na njih. Riječ stakeholder danas upućuje na svakoga ko značajno utječe ili na koga utječe nečije donošenje odluka (Bjeletić, 2009).

Kompanije razlikuju primarne i sekundarne stakeholder-e. Primarni stakeholder-i su oni učesnici koji su direktno pogođeni, bilo pozitivno ili negativno realizacijom određenih akitvnosti kompanije. Sekundarni stakeholder-i su posrednici, različite grupe za pritisak koje se nadovezuju na određene primarne stakeholder-e.

Na Sl.1 su prikazani stakeholder-i povezani sa kompanijom i obostrani odnos između menadžmenta kompanije i njenih interesnih grupa (primarnih i sekundarnih).

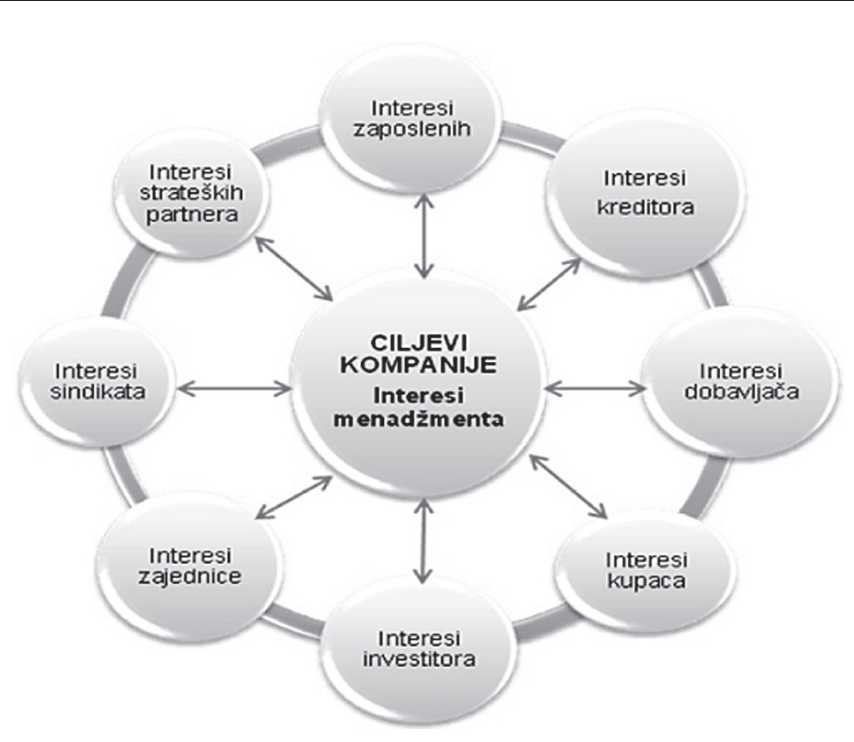

Slika 1. Veza kompanije i stakeholder-a

\subsection{Informacije}

Informaciju je moguće definisati na više načina zavisno u kojem kontekstu, odnosno u kojoj situaciji se ista koristi. Uspješno i kvalitetno upravljati kompanijom ili investirati u neku kompaniju je nezamislivo bez adekvatnih informacija, posebno u vremenu kada su informacione tehnologije doživjele svoju ekspanziju i kada je komunikacija kao savremen alat razmjene informacija veoma razvijena. Da bi uspješno upravljali kompanijom potrebno je mnogo različitih informacija kao što su informacije iz domena finansija i računovodstva, kvantitativne i kvalitativne informacije, tehničkotehnološke i mnoge druge poslovne i neposlovne informacije (Glogić \& Pajević, 2014).

$\mathrm{Na}$ Sl. 2 prikazana je uloga i značaj računovodstvenog informacionog sistema (RIS) u procesu generisanja informacija namjenjenih interesnim grupama. Naime, interesne grupe upućuju zahtjeve kompaniji za informacije, prema upućenim zahtjevima vrši se dizajniranje i prilagodba RIS-a s jedne strane, dok paralelno s druge strane se kontinuirano $u$ isti evidentiraju informacije o poslovnim događajima. Zadatak u skladu sa zahtjevima interesnih grupa, kreira finansijske i sve druge izvještaje i učini ih dostupnim interesnim grupama koje će na osnovu kvalitetnih informacija iz tako kreiranih izvještaja donijeti adekvatne poslovne odluke.

Naime, finansijski izvještaji bi trebali omogućiti dovoljno informacija interesnim grupama (stakeholders) o kompaniji kako bi interesne grupe te informacije koristile kao temelj za sve buduće poslovne i sve druge odluke koje se odnose na kompaniju.

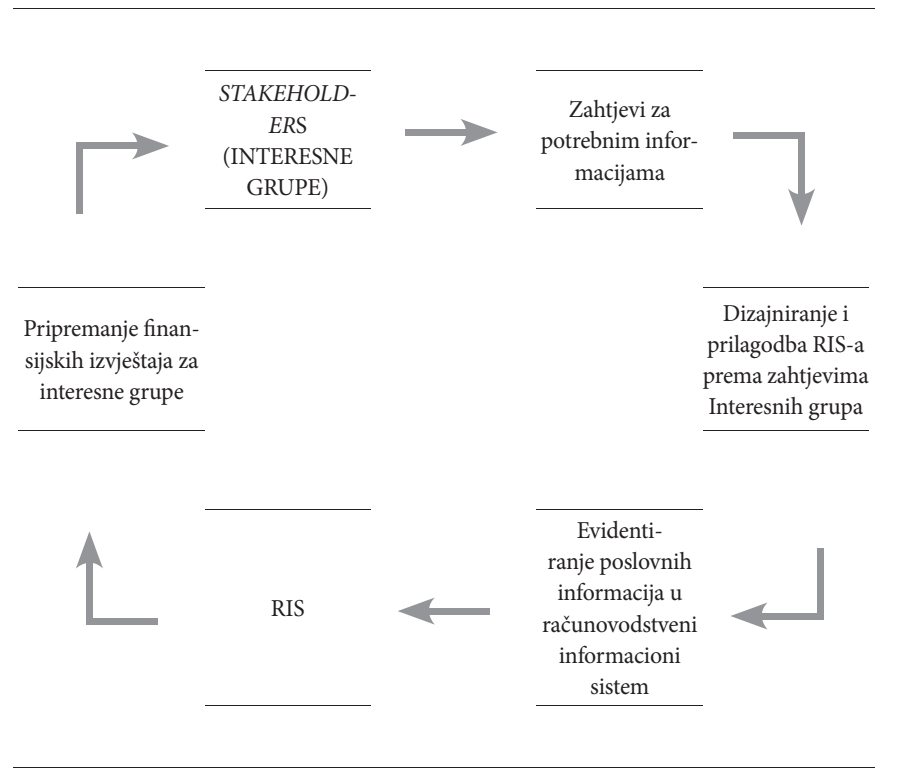

Slika 2. Računovodstvene informacije i interesne grupe Izvor: Reeve \& Warren (2008)

\section{ANALIZA PODATAKA I REZULTATI ISTRAŽIVANJA}

\subsection{Osnovni podaci o istraživanju}

Predmet istraživanja ovog rada je korištenje informacija iz finansijskih izvještaja kompanija od strane interesnih grupa. Istraživanje je bilo fokusirano na utvrđivanje strukture izvora informacija koje koriste različite interesne grupe.

U istraživanju je uzet slučajni uzorak od 72 kompanije: 15 velikih pravnih lica, 21 srednje pravno lice i 36 malih pravnih lica. Metode prikupljanja podataka bile su prilagođene strukturi podataka kroz prikupljanje primarnih podataka na terenu. Korišteno je dopisno komuniciranje putem anketnog upitnika. Dobiveni podaci su obrađeni kroz deskriptivnu statistiku.

Istraživanje je izvršeno u periodu juli - septembar 2015. godine za izvještajni period kompanija od 1.1-31.12.2014. godine.

Svaka interesna grupa ima potrebu za kvalitetnim informisanjem. Osnov istraživanja je bio utvrditi iz kojih izvještaja se koriste informacije, da li je to kompletan set finansijskih izvještaja, samo neki dijelovi finansijskih izvještaja, računovodstvene evidencije, izvještaji koje sačinjavaju eksterno angažovani eksperti, revizorski izvještaji ili treći izvori.

Cilj istraživanja je bio pokazati strukturu izvora informacija koje koriste različite interesne grupe, pri čemu je akcenat istraživanja stavljen na potrebe uprave kompanije, ulagača, kreditora (finansijskih institucija) i državnih organa, čime se željelo ukazati na značaj i ulogu informacija iz finansijskih ili drugih izvještaja. 


\subsection{Rezultati istraživanja - potrebe korisnika za finansijskim izvještajima}

Na Sl. 3 u prvom koraku je utvrđen stepen interesa za informacijama iz finansijskih izvještaja u cilju izdvajanja interesnih grupa koje su značajne za istraživanje.

Najmanji interes za korištenjem informacija iz finansijskih izvještaja pokazali su zaposlenici (2\%), zatim javnost (6\%) i ulagači (7\%).

Značajniji korisnici informacija iz finansijskih izvještaja su kreditori (finansijske institucije) (19\%), državne institucije $(21 \%)$, porezni organi (22\%) i uprava kompanije (23\%).

$\mathrm{Na}$ osnovu ovih rezultata istraživanja, fokus je stavljen na istraživanje izvora informacija za potrebe uprave kompanije, kreditora (finansijskih institucija) i državnih organa. Ulagači su takođe uzeti u obzir, iako je istraživanje pokazalo nizak procenat interesovanja (7\%), a razlog je značaj ulagača u procesu poslovanja kompanija.

\subsection{Rezultati istraživanja - izvori informacija koje koristi uprava prilikom donošenja poslovnih odluka}

Prilikom donošenja poslovnih odluka uprava kompanije koristi informacije iz finansijskih ili nefinansijskih izvještaja.

Istraživanje je pokazalo da se uprava u značajnoj mjeri koristi informacijama iz finansijskih izvještaja, a posebno iz Bilansa uspjeha (25\%), Bilansa stanja (21\%) i Izvještaja o novčanim tokovima (19\%).

Međutim, u strukturi izvora informacija značajno mjesto zauzimaju posebni izvještaji koje priprema računovodstveno u kompaniji (22\%), kao i vlastite evidencije uprave (12\%).

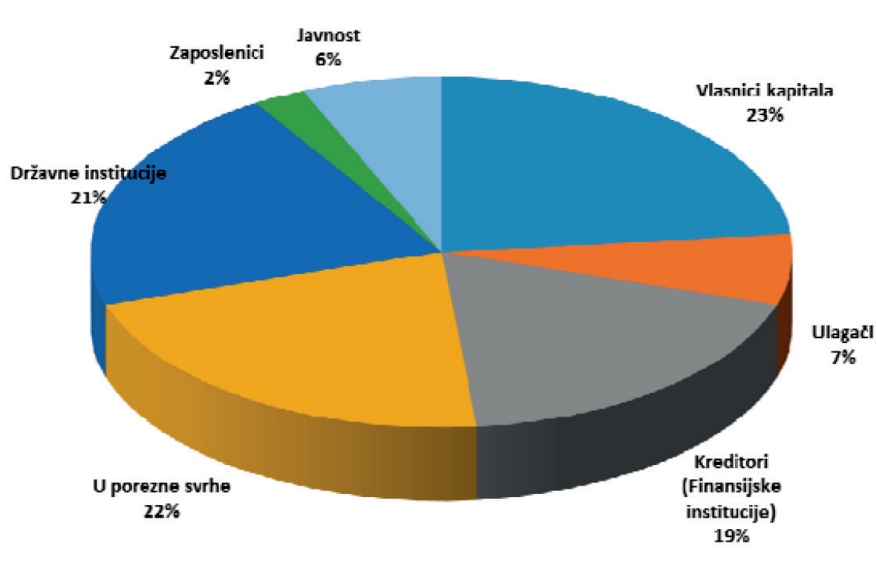

Slika 3. Struktura korisnika finansijskih izvještaja

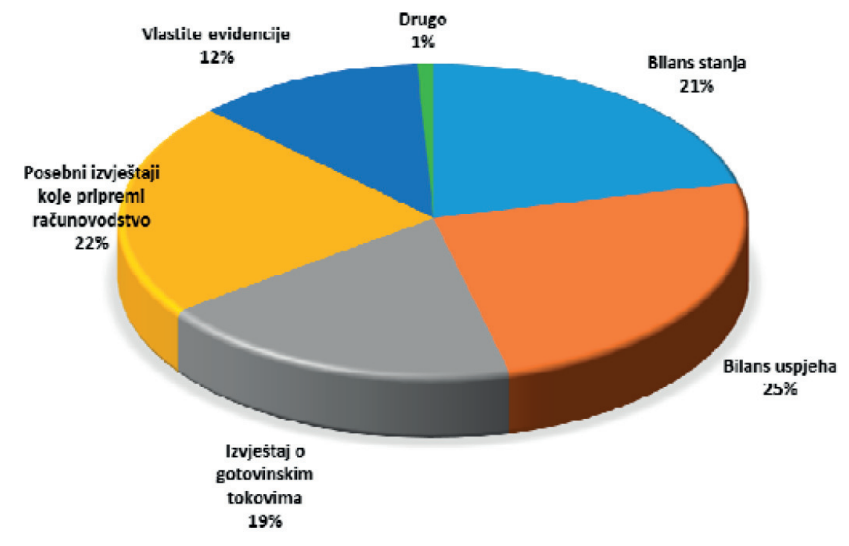

Slika 4. Izvori informacija koje koristi uprava prilikom donošenja poslovnih odluka
$\mathrm{Na}$ Sl. 4 rezultati ukazuju na značajan procenat korištenja informacija iz pojedinačnih dijelova finansijskih izvještaja, ali i na njihovu nedovoljnost u smislu strukture informacija, koja se dopunjuje internim informacijama i vlastitim evidencijama.

\subsection{Rezultati istraživanja - izvori informacija koje koriste ulagači prilikom donošenja poslovnih odluka}

Sl. 5 pokazuje da ulagači kao specifična interesna grupa imaju potrebu za detaljnijim informacijama iz finansijskih izvještaja. Oni u najvećoj mjeri koriste informacije iz kompletnog seta finansijskih izvještaja (31\%), ali fokus stavljaju na Bilans stanja i Bilans uspjeha (16\%) i Izvještaj o novčanom toku (11\%).

Pored informacija iz finansijskih izvještaja u značajnoj mjeri koriste i informacije iz izvještaja eksternog revizora (13\%), posebnih izvještaja koje za njihove potrebe sačine eksterni konsultanti (10\%), i druge izvore informacija (19\%).

\subsection{Rezultati istraživanja - izvori informacija koje koriste kreditori prilikom donošenja poslovnih odluka}

Kreditori kao interesna grupa predstavljaju finansijske institucije koje plasiraju novčana sredstva kompanijama.

Na Sl. 6 istraživanje je pokazalo da se kreditori u značajnom procentu oslanjaju na informacije iz kompletnog seta finansijskih izvještaja (17\%) sa akcentom na informacije iz Bilansa stanja i Bilansa uspjeha (35\%). Pored toga, kreditori koriste i informacije koje se posebno pripremaju za potrebe

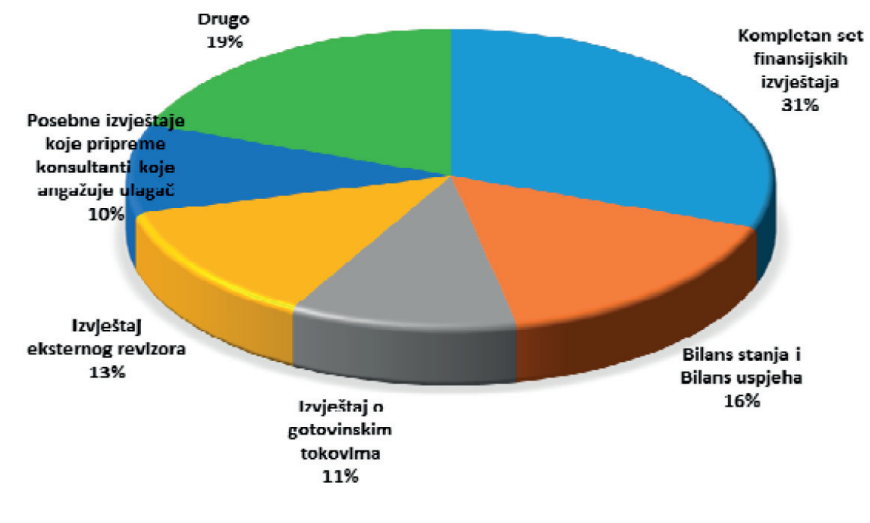

Slika 5. Izvori informacija koje koriste ulagači prilikom donošenja poslovnih odluka

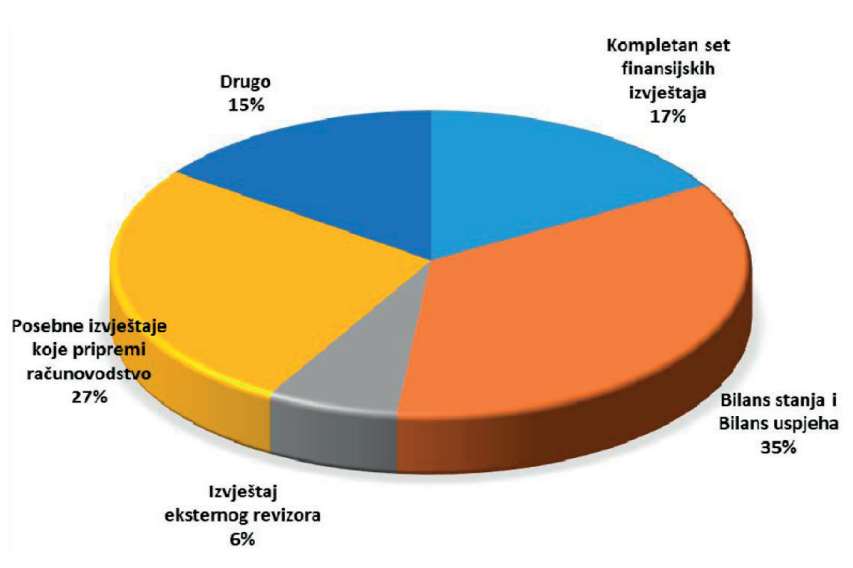

Slika 6. Izvori informacija koje koriste kreditori (finansijske institucije) prilikom donošenja odluka o kreditiranju 
donošenja odluka o plasiranju finansijskih sredstava (27\%), dok u manjoj mjeri koriste informacije iz izvještaja eksternog revizora $(6 \%)$.

Kao i ulagači, kreditori posežu i za drugim izvorima informacija (15\%).

\subsection{Rezultati istraživanja - izvori informacija koje koriste državni organi}

Državni organi u najvećoj mjeri koriste informacije za potrebe analize poslovanja kompanija (statističke analize, definisanje strategije razvoja i sl.) kao i za potrebe kontrole (poreski organi). Sl. 7 pokazuje da su ovoj grupi korisnika potrebne informacije za raznolike spektar potrebe i na osnovu njih donosi odluke različitog karaktera i značaja.

Kompletan set finansijskih izvještaja se ne koristi u značajnoj mjeri (41\%). Posebni izvještaji koji se sačinjavaju interno u kompanijama se koriste u značajnijem procentu (31\%), kao i posebni izvještaji koje pripreme angažovani konsultanti (8\%), zatim drugi izvori (6\%).

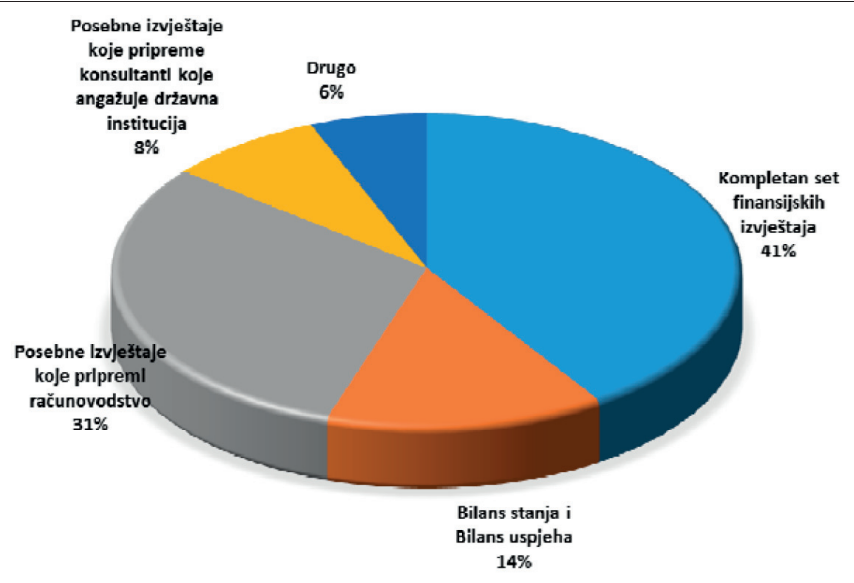

Slika 7. Izvori informacija koje koriste državni organi

\subsection{Rezultati istraživanja - izvori informacija po korisnicima zbirno}

Na Sl. 8 provedeno istraživanje je pokazalo da uprava u najvećoj mjeri koristi informacije iz finansijskih izvještaja, zatim ulagači i kreditori, dok ih najmanje koriste državne institucije. Uprava takođe u najvećoj mjeri koristi i posebne izvještaje (internog karaktera), zatim kreditori i državne institucije.

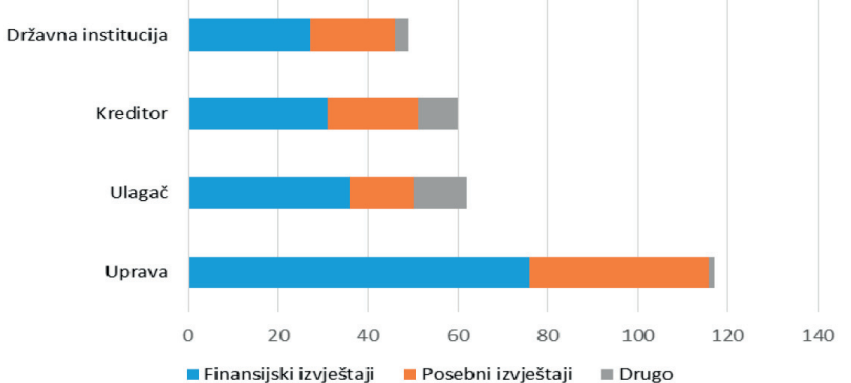

Slika 8. Izvori informacija po korisnicima zbirno

\section{REZIME}

Informacije iz finansijskih izvještaja se koriste od strane interesnih grupa, međutim, potreba za dodatnim informacijama iz drugih izvora upućuje na nedovoljnost strukture i forme finansijskog izvještavanja.

S obzirom na to da je forma i sadržaj finansijskih izvještaja u Bosni i Hercegovini propisana entitetskim Zakonima o računovodstvu i reviziji, koji se naslanjaju na odrednice Međunarodnih računovodstvenih standarda i Međunarodnih standarda finansijskog izvještavanja, preporuka je da se nacionalnom legislativom poboljša finansijsko izvještavanje u smislu dovoljnosti strukture informacija za interesne grupe.

\section{LITERATURA}

Bjeletić, M. (2009). Zainteresovane strane (stejkholderi) identifikacija $i$ analiza. Preuzeto 22. oktobra sa https://jlpmr.files. wordpress.com/2009/12/stejkholderi-bjeletic.ppt

Glogić, E., \& Pajević, M. (2014). Računovodstveni informacioni sistem kao podrška poslovnim finansijama. Finanisijsko izvještavanje u funkciji korporativnog upravljanja (str. 99-100). doi:10.15308/finiz-2014-98-100.

Meigs, W.B., \& Meigs, R.F. (1999). Računovodstvo: Temelj poslovnog odlučivanja. Zagreb: MATE.

Reeve, J.M., \& Warren, C.S. (2008). Principes of financial and managerial accounting, 9th edition. USA: Thomas Higher Education.

\section{THE IMPORTANCE AND USE OF INFORMATION IN FINANCIAL STATEMENTS FOR THE STAKEHOLDERS}

\section{Abstract:}

The aim of this paper is to indicate the importance and the role of financial statements, as they provide information on the financial situation and business performances of a company, which enables different stakeholders to make proper decisions and form attitudes. Information is considered useful if it has an impact on the decision-making process, and significant if its omission could change the decision and attitudes of users of financial statements. This paper aims to analyze the importance of the value of information in financial statements. The sample consists of 72 companies from the real sector on the territory of Bosnia and Herzegovina. The research points to the sources of information used by various stakeholders when making decisions or controlling business operations, as well as the importance of compiling and publishing of financial statements in general. The study also reveals that the results confirm the significant role and wide application of information in financial statements by management, investors, creditors and government institutions. The users of financial statements attempt to make quality business decisions based on the information presented, as quality business decisions depend on the quality of information provided, primarily based on accuracy, reliability and user-friendliness. The research shows that stakeholders continue to use financial statements as the main source of information in the decision-making process and all other financial and non-financial information. Therefore, all users and creators of financial statements need to work on improving the drafting, reporting and use of financial reports and other sources.
Key words:

information,

business decisions,

users of financial statements,

financial reporting. 